\title{
Chemical Deposition of ITO/CdS/PbS/C for Low Voltage Photosensor Applications
}

\author{
C.E. Pérez-García, S. Meraz-Dávila, E.A. Chávez-Urbiola, I.R. Chávez-Urbiola*, \\ F. Willars-Rodríguez, R. Ramírez-Bon, Y. Vorobiev
}

Centro de Investigación y de Estudios Avanzados del IPN. Unidad Querétaro Apdo. Postal 1-798, 76001, Querétaro, Qro., México.

*Texas Materials Institute, The University of Texas, Austin, Texas 78712

*E-mail: rrbon@ cinvestav.mx

doi: $10.20964 / 2018.04 .22$

Received: 13 November 2017 / Accepted: 12 January 2018 / Published: 6 March 2018

In this work we report the assembling and electrical characterization of $\mathrm{ITO} / \mathrm{CdS} / \mathrm{PbS} / \mathrm{C}$ heterostructured photosensor. The assembling of the photosensor was done completely by solution processing, employing the chemical bath deposition (CBD) technique to deposit both semiconductor layers in the device, $\mathrm{CdS}$ and $\mathrm{PbS}$. ITO-coated glass was used as substrate and graphite ink electrodes as back contacts. The electrical output response of the photodevices was analyzed in dark and under illumination at different intensities. Its sensitivity was examined working as photodiode at zero volts. The results showed the rectifying character of the heterostructure and light sensitivity with linear photoresponse under illumination. The measured photoresponsivity of the photosensor was $1.22 \mathrm{~A} / \mathrm{W}$, which is around $50 \%$ of an ideal characteristic of a sensor for a given spectral range.

Keywords: photosensors; hybrid photodiodes; solution growth; chemical deposition.

\section{$\underline{\text { FULL TEXT }}$}

(C) 2018 The Authors. Published by ESG (www.electrochemsci.org). This article is an open access article distributed under the terms and conditions of the Creative Commons Attribution license (http://creativecommons.org/licenses/by/4.0/). 